\title{
Fluid loading during spinal anesthesia can reduce bradycardia after intravenous dexmedetomidine infusion
}

Received May 16, 2018

Revised 1st, July 30, 2018

2nd, August 5, 2018

3rd, August 17, 2018

Accepted August 23, 2018

\section{Corresponding author \\ Se Hun Lim, M.D., Ph.D. \\ Department of Anesthesiology and \\ Pain Medicine, Busan Paik Hospital, Inje University College of Medicine, 75 Bokji-ro, Busanjin-gu, Busan 47392, Korea \\ Tel: 82-51-890-6520 \\ Fax: 82-51-898-4216 \\ E-mail: anespc@naver.com \\ ORCID \\ https://orcid.org/0000-0001-8450-0595}

\section{Wonjin Lee ${ }^{1,2}$, Yongjae Han', Se Hun Lim', Sung-ho Moon', Kwangrae Cho', and Myoung-hun Kim ${ }^{1}$}

${ }^{1}$ Department of Anesthesiology and Pain Medicine, Busan Paik Hospital, Inje University College of Medicine, ²Paik Institute for Clinical Research, Inje University College of Medicine, Busan, Korea

Background: Dexmedetomidine has been widely used during spinal anesthesia to provide sedation. However, dexmedetomidine frequently causes significant bradycardia. This study was designed to evaluate whether fluid loading could reduce the incidence of bradycardia after intravenous dexmedetomidine infusion in patients under spinal anesthesia.

Methods: A total of 99 patients, 18 to 65 years of age, with American Society of Anesthesiologists physical status 1 or 2 , who were scheduled for elective total knee replacement or internal fixation of lower leg fracture under spinal anesthesia were enrolled. The patients were randomly assigned into one of the three groups, and fluid was loaded as follows: group LOW - $4 \mathrm{ml} / \mathrm{kg}$, group MID - $8 \mathrm{ml} / \mathrm{kg}$, and group $\mathrm{HI}-12 \mathrm{ml} / \mathrm{kg}$. After fluid loading and spinal anesthesia, dexmedetomidine was infused as follows: $1 \mu \mathrm{g} / \mathrm{kg}$ of loading dose for 10 minutes, thereafter continuous infusion at $0.4 \mu \mathrm{g} / \mathrm{kg} / \mathrm{h}$.

Results: The heart rate of group $\mathrm{HI}$ was significantly higher than that of group LOW ( $\mathrm{P}=$ 0.049). The dosage of atropine administration was significantly lower in group $\mathrm{HI}$ than in group LOW $(P=0.003)$. The change in thoracic fluid contents was significantly higher in group $\mathrm{HI}$ than in group LOW $(\mathrm{P}=0.018)$.

Conclusions: Fluid loading during spinal anesthesia can reduce the incidence and extent of bradycardia after intravenous dexmedetomidine infusion.

Keywords: Bradycardia; Dexmedetomidine; Fluid therapy; Heart rate; Spinal anesthesia.

\section{INTRODUCTION}

Spinal anesthesia has offered sufficient and safe surgical conditions in lower limb surgery. Spinal anesthesia has provided not only cardiovascular and respiratory stability and rapid postoperative recovery from the perspectives of anesthesiologists, but also involves no loss of consciousness and affords early food intake for the patients [1]. However, patients should stay awake under spinal anesthesia without sedative drugs. This could make patients feel anxiety and stress $[2,3]$. To reduce the anxiety and stress of patients under spinal anesthesia, diverse sedative drugs have been used. Among them, dexmedetomidine has been widely used for sedation [4-10]. However, dexmedetomidine frequently causes significant bradycardia, which requires additional therapy, including atropine sulfate or the discontinuation of dexmedetomidine administration $[6-8,11,12]$.

Spinal anesthesia itself commonly causes bradycardia [13].

This is an Open Access article distributed under the terms of the Creative Commons Attribution Non-Commercial License (http://creativecommons.org/licenses/by-nc/4.0) which permits unrestricted non-commercial use, distribution, and reproduction in any medium, provided the original work is properly cited.

Copyright (c) the Korean Society of Anesthesiologists, 2019 
The occurrence of bradycardia after spinal anesthesia can often be explained due to the blocking of the cardiac accelerator fiber at the T1-T4 level. However, even with low level spinal anesthesia (below T4), heart rate (HR) decreased by about $10 \%$ from baseline, and this reduction in HR cannot be explained by the blocking of the heart accelerator fiber. This phenomenon is often explained by Bainbridge reflex: decreased intravascular volume status decreases the activity of atrial stretch receptor activity, resulting in bradycardia. Indeed, some studies have shown that manipulation which increases venous return, such as raising the legs or assuming a head-down position, increases heart rate in patients with bradycardia after spinal anesthesia $[13,14]$.

In spite of the fact that the reported incidence of bradycardia after dexmedetomidine infusion is up to $30-40 \%$ $[6-8,11,12]$, authors experience more frequent bradycardia after dexmedetomidine administration in patients with spinal anesthesia in the clinical field. The combination of dex- medetomidine and spinal anesthesia may cause bradycardia more frequently, though no previous report about this could be found. In this paper, the authors propose the hypothesis that sufficient fluid loading will decrease the HR reduction by Bainbridge reflex, thereby reducing the incidence of bradycardia after dexmedetomidine administration in patients under spinal anesthesia. To verify this hypothesis, the HRs were measured during dexmedetomidine infusion in patients who received the fluid loading $(4 \mathrm{ml} / \mathrm{kg}, 8 \mathrm{ml} / \mathrm{kg}$ and $12 \mathrm{ml} / \mathrm{kg}$ ) during spinal anesthesia.

\section{MATERIALS AND METHODS}

The present study was approved by our university Institutional Review Board (IRB no. 16-0154). Written consent was obtained from all subjects who agreed to be involved in this study.

The 99 patients were enrolled through the Consolidated Enrollment

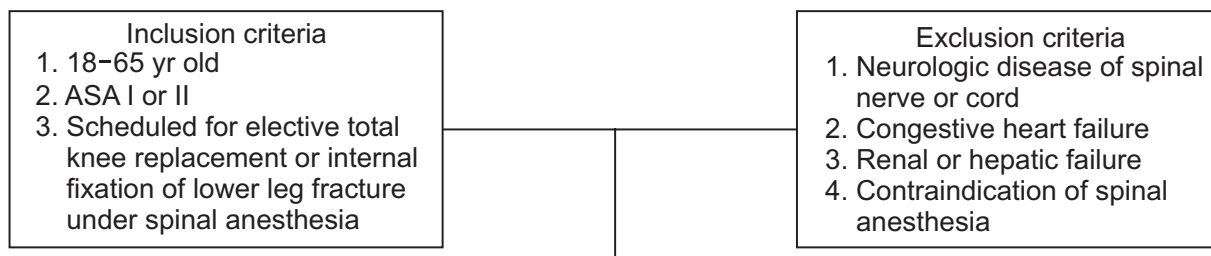

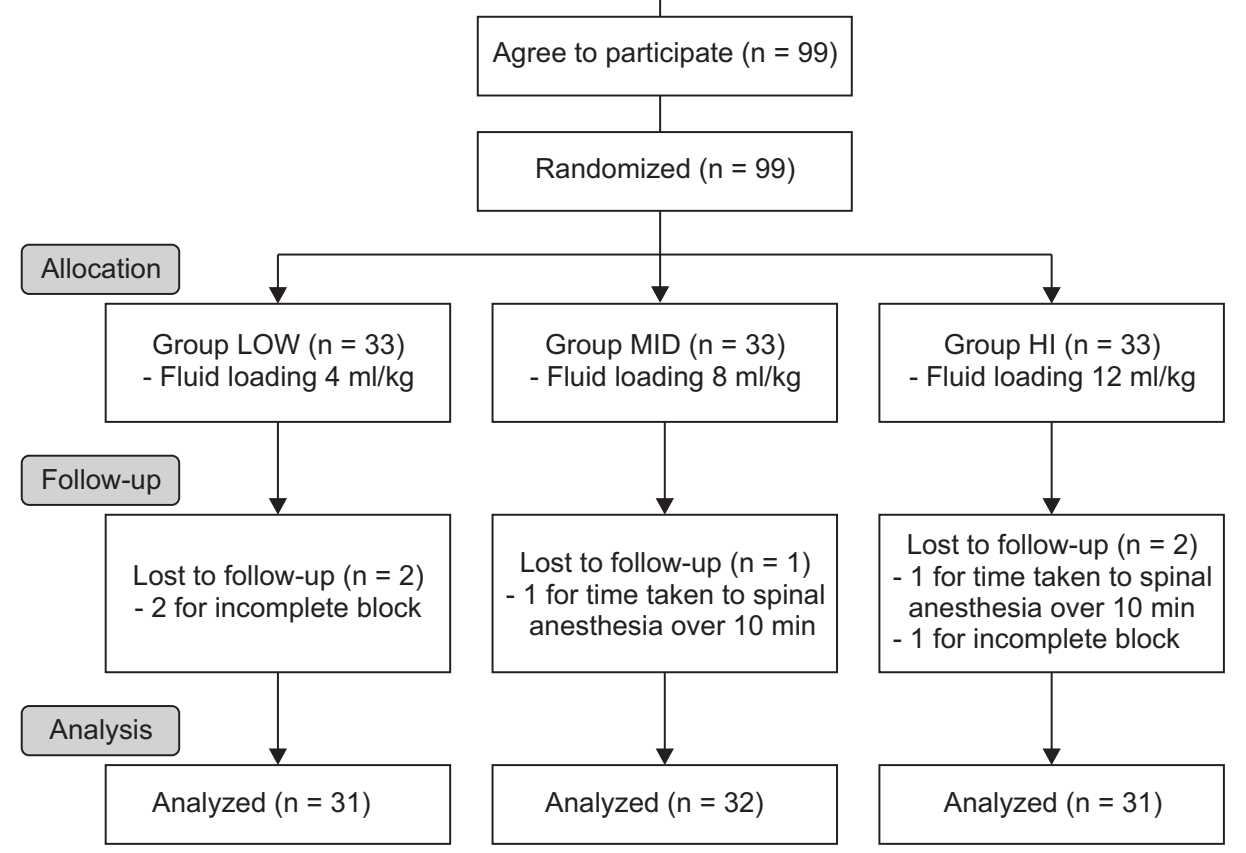

Fig. 1. Consolidated Standards of Reporting Trials (CONSORT) flow chart. ASA: American Society of Anesthesiologists physical status. 
Standards of Reporting Trials (CONSORT) process, as illustrated in Fig. 1. The inclusion criteria were as follows: aged 18 to 65 years old with 1 or 2 American Society of Anesthesiologists physical status, and scheduled for elective unilateral total knee replacement or internal fixation of unilateral lower leg fracture with over 1 hour under spinal anesthesia. The exclusion criteria included patients with underlying neurologic disease of spinal nerve or spinal cord; cardiovascular disease; renal or hepatic failure; and contraindications of spinal anesthesia such as bleeding tendency or patient refusal. The experimental withdrawal criteria were spinal sensory block level under $\mathrm{T} 10$ or over $\mathrm{T} 4$, and the time taken to spinal anesthesia being over the planned time (10 minutes).

After the patient arrived at the operating room, electrocardiogram, non-invasive blood pressure, pulse oximetry, and non-invasive cardiac output monitoring (NICOM, Cheetah medical Inc., USA) were monitored, and the initial values of $\mathrm{HR}$, mean blood pressure (MBP), oxygen saturation $\left(\mathrm{SpO}_{2}\right)$, and thoracic fluid content (TFC) were measured. The HR, $\mathrm{MBP}, \mathrm{SpO}_{2}$, and change in TFC from initial value (TFCd) were recorded every 5 minutes. The level of sedation was evaluated using the Ramsay Sedation Scale (RSS: 1, awake, patient anxious, agitated, or restless; 2 , awake, patient cooperative, oriented, and tranquil; 3 , awake, patient response to commands only; 4, asleep, brisk response to light glabellar tap or loud auditory stimulus; 5 , asleep, sluggish response to light glabellar tap or loud auditory stimulus; and 6, asleep, no response to light glabellar tap or loud auditory stimulus) [15] every 5 minutes after the dexmedetomidine infusion started.

In the pilot study, the HR after dexmedetomidine (Prece$\operatorname{dex}^{\circledast}$, Hospira Korea Co., Korea) infusion $(1 \mu \mathrm{g} / \mathrm{kg}$ of loading dose for 10 minutes, thereafter continuous infusion of $0.4 \mu \mathrm{g} /$ $\mathrm{kg} / \mathrm{h}$ rate) was measured in two groups ( $\mathrm{n}=5$ in each group). The dose of dexmedetomidine was determined according to previous studies $[2,6,11,12,16]$. During spinal anesthesia, patients from each group were administered $4 \mathrm{ml} / \mathrm{kg}$ (group 1) or $12 \mathrm{ml} / \mathrm{kg}$ (group 2) of normal saline over 30 minutes. After 10 minutes of loading dose infusion, HRs were $59.2 \pm 7.0$ in group 1 and $64.3 \pm 8.0$ in group 2. The calculated sample size with alpha value 0.05 and power value $80 \%$ was 30 in each group. Considering $10 \%$ rate loss, the final sample size was determined to be 33 in each group.

The patients were randomly assigned into one of the three groups: fluid loading of either $4 \mathrm{ml} / \mathrm{kg}$ (group LOW), $8 \mathrm{ml} / \mathrm{kg}$ (group MID), and $12 \mathrm{ml} / \mathrm{kg}$ (group HI). The experiment was carried out as stated in Fig. 2.

The patients were fasted for $8 \mathrm{~h}$ and administered maintenance fluids during this fasting period according to the Parkland formula; no premedication was administered. Then, the normal saline (CJ HealthCare Co., Korea) infusion of the prescribed amount was started for each group. To minimize observer bias, the fluids were covered with an opaque cover by a third party. Spinal anesthesia was induced 10 minutes after fluid loading. The patients were placed in the lateral decubitus position and their dura maters were punctured with 25-guage Whitacre spinal needle (Becton Dickinson, USA) at L4-L5. Then, hyperbaric $0.5 \%$ bupivacaine (Hana bupivacaine chloride heavy ${ }^{\circledR}$, Hana Pharm Co., Korea) 9 to $10 \mathrm{mg}$ was administered intrathecally at a rate of $0.2 \mathrm{ml} / \mathrm{sec}$. Sensory block level was evaluated by pin-prick test with 25-gauge needle every two minutes until 10 minutes after anesthesia and every 10 minutes thereafter. Spinal anesthesia was performed by one highly skilled anesthesiologist, and if the process of spinal anesthesia was not performed in the planned

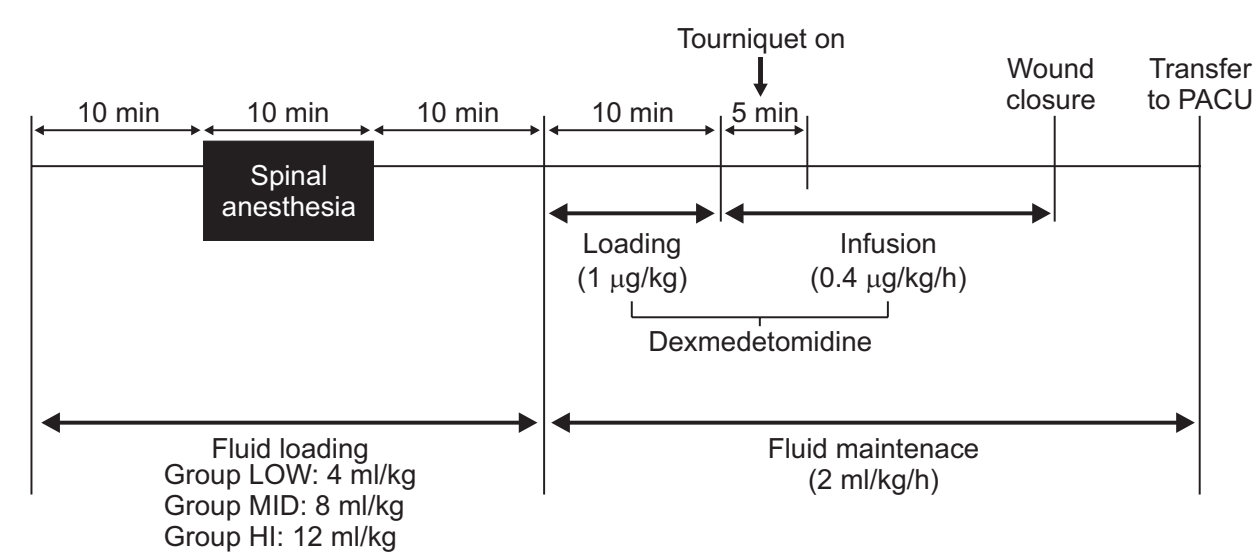

Fig. 2. Schematic timetable of experiment. PACU: post anesthetic care unit. 
10 minutes, the case was excluded from analysis.

Ten min after spinal anesthesia, the dexmedetomidine infusion was started: $1 \mu \mathrm{g} / \mathrm{kg}$ of loading dose was infused for 10 minutes, then $0.4 \mu \mathrm{g} / \mathrm{kg} / \mathrm{h}$ of maintenance dose was infused continuously. After fluid loading had continued for over 30 minutes, the existing fluids were replaced with new fluid by a third party and fluid infusion rate was unified to $2 \mathrm{ml} / \mathrm{kg}$ / $\mathrm{h}$ in all groups. All patients were supplied oxygen via a nasal catheter with $2 \mathrm{~L} / \mathrm{min}$ flow. A tourniquet was inflated 10-15 minutes after dexmedetomidine infusion and deflated before wound closure. The volume deficiency after tourniquet deflation was defined as decreased TFC and over $20 \%$ decrease of MBP after deflation of the tourniquet. If volume deficiency developed after tourniquet deflation, fluid was loaded until the TFC and MBP recovered to their previous values. Continuous infusion of dexmedetomidine was stopped when wound closure started. After the operation, patients stayed at least $20 \mathrm{~min}$ in the post anesthetic care unit (PACU), until the sensory blockade level fell below L10.

The expected adverse effects by dexmedetomidine or spinal anesthesia were treated as follows: Hypotension was defined as mean blood pressure under $60 \mathrm{mmHg}$ and treated with $5 \mathrm{mg}$ of intravenous (IV) ephedrine (Daewon ephedrine chloride ${ }^{\circledR}$, Daewon Pharm Co., Korea). Bradycardia was defined as HR under 50 beats/min and treated with $0.5 \mathrm{mg}$ of IV atropine (Jeil atropine sulfate ${ }^{\circledR}$, Jeil Pharm Co., Korea). When a patient showed both hypotension and bradycardia, it was treated with $5 \mathrm{mg}$ of IV ephedrine. If the patient showed the uncontrollable bradycardia or hypotension despite three consequent drug administrations, dexmedetomidine infusion was ceased and followed by inotropics or vasopressor infusion. If the level of sedation was insufficient (RSS 1 or 2), the maintenance dose of dexmedetomidine was gradually increased by $0.1 \mu \mathrm{g} / \mathrm{kg} / \mathrm{h}$. If the patients showed excessive sedation (RSS 6) or hypoxemia $\left(\mathrm{SpO}_{2}<90 \%\right)$, dexmedetomidine infusion was ceased until RSS or $\mathrm{SpO}_{2}$ recovered. If the patient complained of nausea and vomiting, it was treated with $4 \mathrm{mg}$ of IV ondansetron (Boryung onsetron injection ${ }^{\circledR}$, Boryung Pharm Co., Korea).

All measured data are shown as mean \pm standard deviation (SD). Differences of non-continuity variables among groups were analyzed using chi-square test and Fisher's exact test. The post-hoc analysis of non-continuity variables were performed with Bonferroni correction ( $\mathrm{P}$ values multiplied by 3). Consequent $\mathrm{HR}, \mathrm{MBP}, \mathrm{SpO}_{2}$, and TFCd were analyzed using repeated measured ANOVA and post-hoc analysis was performed by Bonferroni analysis. The normal distribution of continuous parameters was analyzed using the KolmogorovSmironov test. The normally distributed data were analyzed using ANOVA and a post-hoc analysis was performed by Bonferroni analysis. If the data did not follow a normal distribution, the Kruskal-Wallis test and Mann-Whitney $U$ test were used. The statistical analysis was conducted using SPSS version 18 (IBM Co., USA) and P values below 0.05 were assumed to be statistically significant.

Table 1. Baseline Characteristics

\begin{tabular}{|c|c|c|c|c|}
\hline Variable & Group LOW $(n=22)$ & Group MID $(n=22)$ & Group HI $(n=21)$ & P value \\
\hline Age (yr) & $45.2 \pm 14.3(38.9-51.5)$ & $49.4 \pm 13.6(43.3-55.4)$ & $50.9 \pm 15.5(43.9-57.9)$ & 0.408 \\
\hline $\operatorname{Sex}(M / F)$ & $12 / 10$ & $14 / 8$ & $10 / 11$ & 0.606 \\
\hline Weight (kg) & $64.9 \pm 11.4(59.8-70.0)$ & $69.4 \pm 9.0(65.4-73.4)$ & $64.1 \pm 10.4(59.4-68.8)$ & 0.196 \\
\hline Height (cm) & $162.8 \pm 9.5(158.6-167.0)$ & $167.2 \pm 8.0(163.6-170.7)$ & $162.6 \pm 7.6(159.1-166.0)$ & 0.134 \\
\hline ASA PS (I/II) & $16 / 6$ & $12 / 10$ & $12 / 9$ & 0.479 \\
\hline Type of operation & & & & 0.758 \\
\hline Total knee replacement & 7 & 10 & 9 & \\
\hline Lower limb fracture & 15 & 12 & 12 & \\
\hline Highest sensory block level, thoracic & $7.8 \pm 1.6(7.1-8.5)$ & $7.6 \pm 1.5(7.0-8.3)$ & $7.7 \pm 1.5(7.1-8.4)$ & 0.924 \\
\hline OP time (min) & $98.4 \pm 21.7(88.8-108.0)$ & $94.8 \pm 18.4(86.6-102.9)$ & $98.3 \pm 23.5(87.6-109.0)$ & 0.812 \\
\hline \multicolumn{5}{|l|}{ Dose of dexmedetomidine $(\mu \mathrm{g})$} \\
\hline Bolus & $65.6 \pm 10.9(60.7-70.4)$ & $69.7 \pm 8.9(65.8-73.7)$ & $64.9 \pm 10.6(64.0-69.7)$ & 0.242 \\
\hline Maintenance & $33.8 \pm 11.9(28.5-39.0)$ & $34.5 \pm 9.2(30.5-38.6)$ & $33.8 \pm 14.0(27.5-40.2)$ & 0.973 \\
\hline Total & $99.4 \pm 20.0(90.5-108.2)$ & $104.3 .9 \pm 15.1(97.6-110.9)$ & $98.7 \pm 21.9(88.7-108.7)$ & 0.582 \\
\hline
\end{tabular}

Values are presented as mean \pm SD (95\% confidence interval) or number of patients. Group LOW: fluid loading 4 ml/kg, Group MID: fluid loading 8 $\mathrm{ml} / \mathrm{kg}$, Group HI: fluid loading $12 \mathrm{ml} / \mathrm{kg}$. ASA PS: American Society of Anesthesiologists physical status, OP time: operation time. 


\section{RESULTS}

Baseline characteristics are shown in Table 1 and there were no significant differences among groups. A total of five patients were excluded from the experiment, three due to incomplete spinal anesthesia and two due to the time taken to
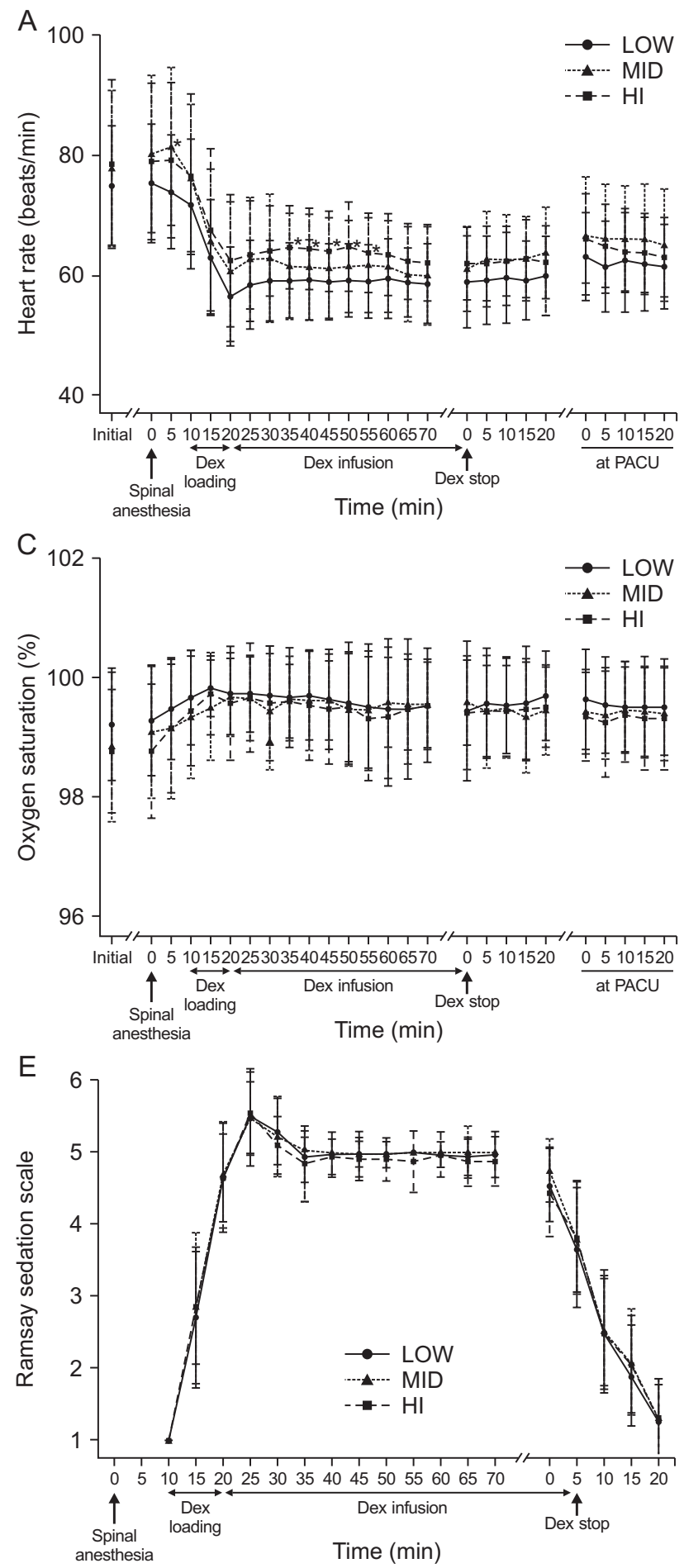

spinal anesthesia being over the planned 10 minutes (Fig. 1). In order to describe the results easily, the time course of experiment was divided into four sections: initial period (before fluid administration), post-spinal period (from the spinal anesthesia to 70 minutes after), dex-stop period (from the stoppage of dexmedetomidine infusion to 20 minutes after), and
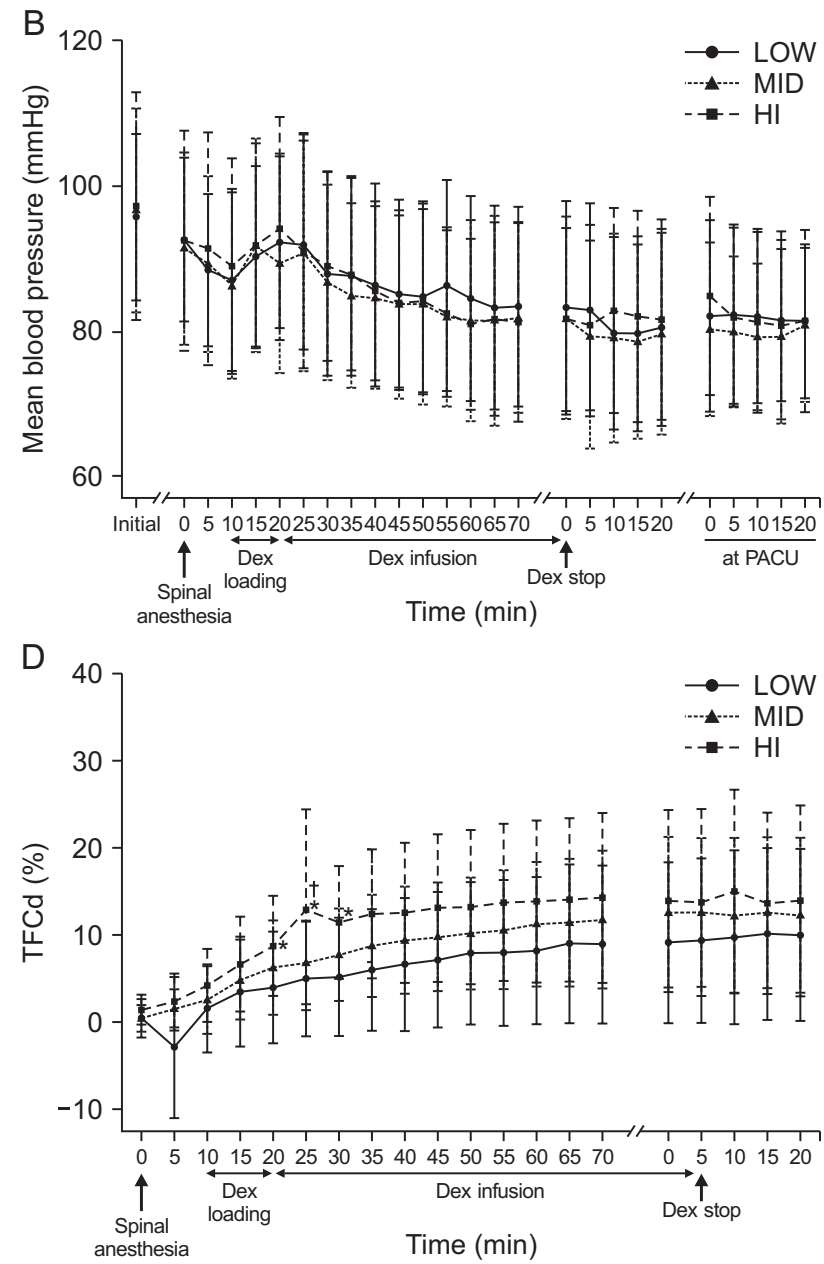

Fig. 3. The heart rate (A), mean blood pressure (B), oxygen saturation (C), change in thoracic fluid contents from initial value (TFCd) (D), and Ramsay sedation scale (E) over time. Group LOW: fluid loading $4 \mathrm{ml}$ kg, Group MID: fluid loading $8 \mathrm{ml} / \mathrm{kg}$, Group Hl: fluid loading $12 \mathrm{ml}$ kg. Dex: dexmedetomidine, PACU: post anesthetic care unit. $* \mathrm{P}<0.05$ when compared with group LOW, ${ }^{\dagger} \mathrm{P}<0.05$ when compared with group MID. 
at PACU (from PACU arrival to 20 minutes after). There was no case of additional fluid administration due to developed volume deficiency after tourniquet deflation in this experiment.

The HR, MBP, and $\mathrm{SpO}_{2}$ over time are shown in Fig. 3. The initial $\mathrm{HR}, \mathrm{MBP}$, and $\mathrm{SpO}_{2}$ were not significantly different among the groups ( $\mathrm{P}$ values were $0.486,0.913$, and 0.218 , respectively). The post-spinal HRs were significantly different among groups ( $\mathrm{P}=0.034)$, especially the group $\mathrm{HI}$, which showed significantly higher HRs than group LOW $(\mathrm{P}=0.049)$. Further, HRs between post-spinal 35 to 55 minutes were higher in group HI than in group LOW (P values were 0.013, $0.023,0.019,0.008$ and 0.025 , respectively; Fig. $3 \mathrm{~A})$. In the dex-stop period and at PACU, HRs did not show significant differences among groups ( $\mathrm{P}$ values were 0.064 and 0.228 , respectively).

The MBPs were not significantly different among groups over the entire experimental period ( $\mathrm{P}=0.874$; Fig. $3 \mathrm{~B}$ ). Also, $\mathrm{SpO}_{2}$ values were not significantly different among groups over the entire experimental period ( $\mathrm{P}=0.600$; Fig. $3 \mathrm{C})$.

The mean TFCd values increased as the amount of fluid loading increased over the experiment period, and significant differences were found among groups $(\mathrm{P}=0.022)$, with group $\mathrm{HI}$ showing significantly higher TFCds than group LOW $(\mathrm{P}=$ 0.018). At the specific time points (post-spinal 5 and 20 to 60 minutes), TFCd was higher in group $\mathrm{HI}$ than in group LOW (P values were $0.018,0.006,0.001,0.001,0.001,0.006,0.008,0.03$, 0.019, and 0.025, respectively; Fig. 3D).

Bradycardia was present in 18 patients in group LOW (58.1\%), 10 patients in group MID (31.3\%), and five patients in group HI (16.1\%), and showed significant differences among groups $(\mathrm{P}=0.002)$, with group $\mathrm{HI}$ showing significant lower bradycardia than group LOW (Bonferroni corrected $\mathrm{P}=0.003$ ). However, group MID did not show a statistically significant difference when compared with groups $\mathrm{HI}$ and LOW (Bonferroni corrected P values were 0.711 and 0.132 , respectively). The administered dosages of atropine were $0.35 \pm$ $0.37,0.17 \pm 0.3$, and $0.10 \pm 0.24 \mathrm{mg}$ in groups LOW, MID, and $\mathrm{HI}$, respectively $(\mathrm{P}=0.003)$, with group $\mathrm{HI}$ showing significant lower atropine administration than group LOW $(\mathrm{P}=0.003)$. However, group MID did not show a statistically significant difference when compared with group HI and LOW (P values were 0.963 and 0.051 , respectively).

Hypotension was present in five patients in group LOW
(16.1\%), five patients in group MID (15.6\%), and three patients in group $\mathrm{HI}(9.7 \% ; \mathrm{P}=0.714)$, and hypotension was always accompanied by bradycardia in the present study. The administered dosages of ephedrine were $0.97 \pm 2.39,1.09 \pm$ 3.04 , and $0.65 \pm 2.14 \mathrm{mg}$ in group LOW, MID, and HI, respectively $(\mathrm{P}=0.774)$. Nausea and vomiting were present in three patients in group LOW $(9.7 \%)$, one patient in group MID (3.1\%), and zero patients in group HI $(0 \% ; \mathrm{P}=0.156)$. The administered dosages of ondansetron were $0.39 \pm 1.20,0.13 \pm$ 0.70 , and $0 \mathrm{mg}$ in groups LOW, MID, and $\mathrm{HI}$, respectively $(\mathrm{P}=$ 0.156). Hypoxemia was not found in this experiment. In addition, all patients in the present study showed $\mathrm{SpO}_{2}$ over $96 \%$. The RSS was not significantly different among groups in this experiment (Fig. 3E).

\section{DISCUSSION}

The present study demonstrated that $12 \mathrm{ml} / \mathrm{kg}$ of fluid loading during spinal anesthesia significantly reduces the incidence and extent of bradycardia when compared with 4 $\mathrm{ml} / \mathrm{kg}$ of fluid loading. The mean HR values of each group increased by the amount of fluid loading in a dose-dependent manner and showed a statistically significant difference between groups LOW and HI $(\mathrm{P}=0.049)$. The HRs of group HI were maintained higher, especially post-spinal 35-55 minutes, than group LOW (Fig. 3A). Interestingly, TFCd were higher in group HI than group LOW between post-spinal 20 and 60 minutes (Fig. 3D). This maintenance of higher HRs and elevation of TFCd seems to have a close temporal relation. Though the exact mechanism of these results is difficult to verify, it is considered that the fluid preloading increased the TFC, hence HR was maintained higher by increased venous return.

Dexmedetomidine is an $\alpha 2$-adrenoceptor agonist and has been used as a sedative-analgesic [17]. IV dexmedetomidine infusion after spinal anesthesia has been widely performed in the clinical field, since it provides many advantages including: increasing the quality and duration of sensorymotor blocking [4-10], prolonging postoperative analgesia [4-6], providing an anti-shivering effect [18], and affording sedation with minimal respiratory depression [19], thereby reducing patient physiological and psychological stress [2,3]. Moreover, dexmedetomidine improves patient satisfaction with spinal anesthesia, thereby increasing patient acceptance 
for spinal anesthesia [1]. However, bradycardia requiring IV atropine is very common after IV dexmedetomidine infusion $[5-8,11,12]$. High doses and rapid infusion of dexmedetomidine have been known to cause transient hypertension and reflex bradycardia followed by hypotension [20,21]. Bradycardia by dexmedetomidine is caused by the decreased release of noradrenaline from the sympathetic nervous system, mediated by $\alpha 2 \mathrm{~A}$-adrenoceptor [17]. Also, spinal anesthesia itself is known to reduce HR [13,22]. Even though bradycardia often occurred in spinal blockade under T4, the mechanism of HR reduction after spinal anesthesia has been explained by the blocking of the cardiac accelerator fiber at T1-T4. Sancetta et al. [13,22] reported that HR was reduced about $10 \%$ from baseline despite spinal blockade under T4. Carpenter et al. [23] also reported that decreased HR after spinal anesthesia exceeded the HR reduction with complete cardiac sympathetic denervation. Baron et al. [24] measured baroreflex activity after T8-T12 epidural blockade and showed that low level epidural blockade reduced the venous return, thereby enhancing cardiac vagal activity sufficiently to prevent the arterial baroreceptor-mediated HR increase. These accumulated evidences suggested that the occurrence of bradycardia after low level spinal blockade was due to Bainbridge reflex, caused by the decreased venous return [13] rather than blocking of the cardiac accelerator fiber. In the present study, patients with spinal blockade under T4 were targeted to clarify the effect of fluid loading without the possibility of blocking cardiac accelerator fiber. And the higher HR and lower incidence of bradycardia in group HI may be due to the increased venous return by the fluid loading.

To access the volume status of patient, the present study measured TFCd using NICOM. TFC is calculated from the measured thoracic impedance and used to access thoracic fluid level noninvasively. The absolute TFC value itself did not correlate with fluid loss, though the change in TFC (TFCd) correlated well with fluid deficits [25]. Although TFCd has not been studied often and is doubtful in terms of reliability, the present study showed significantly lower TFCd 5 minutes after spinal block in group LOW, as compared to groups MID and HI (Fig. 3D). In addition, TFCd in group HI significantly increased when compared with group LOW and MID after tourniquet inflation. These results may enhance the reliability of TFCd a little bit. The present study showed higher TFCd in group HI than in group LOW between post-spinal 20 and
60 minutes (Fig. 3D). This result also demonstrates that the increase in HR might be due to the increase in venous return.

The previously reported incidences of bradycardia and hypotension after dexmedetomidine administration in patients with spinal anesthesia were about $10-40 \%$ and 5-15\%, respectively $[5,6,11,12,16]$. Dinesh et al. [6] reported $24 \%$ of bradycardia and $14 \%$ of hypotension after $1 \mu \mathrm{g} / \mathrm{kg}$ loading dose, followed by a $0.5 \mu \mathrm{g} / \mathrm{kg} / \mathrm{h}$ maintenance dose of dexmedetomidine administration in patients with spinal anesthesia. They preloaded $10 \mathrm{ml} / \mathrm{kg}$ of crystalloid before spinal anesthesia. Whizar-Lugo at al. [16] reported $32 \%$ of bradycardia and $8 \%$ of hypotension after $1 \mu \mathrm{g} / \mathrm{kg}$ loading dose, followed by a $0.5 \mu \mathrm{g} / \mathrm{kg} / \mathrm{h}$ maintenance dose of dexmedetomidine administration in patients with spinal anesthesia. They preloaded 500-1,000 $\mathrm{ml}$ of crystalloid before spinal anesthesia. Compared with the present study, these studies used dosages of dexmedetomidine and amounts of fluid preloading of group MID and HI similar to those used by the present study. In the present study, the incidence of bradycardia was $31.3 \%$ in group MID and $16.1 \%$ in group $\mathrm{HI}$, and the incidences of hypotension were $15.6 \%$ in group MID and $9.7 \%$ in group HI, which were similar to previous studies. However, the incidence of bradycardia (58.1\%) in group LOW was higher than those of previous studies. This may result from the fact that the amount of fluid preloading in group LOW was lower than those of previous studies.

In the present study, hypotension manifested less often than bradycardia. The incidence was decreased dose dependently as the amount of fluid infusion was increased, though these were not statistically different $(P=0.714)$. In previous studies, dexmedetomidine did not increase the incidence of hypotension after spinal anesthesia [5,26], and the present study also showed a similar incidence of hypotension. Therefore, hypotension may not be affected by dexmedetomidine.

Fluid preloading during spinal anesthesia often has been executed to prevent hypotension. In addition, the present study showed that fluid preloading during spinal anesthesia can decrease the incidence and extent of bradycardia after intravenous dexmedetomidine infusion. However, for clinical application, anesthesiologists must consider the risks and benefits of fluid preloading. First, there have been controversies about the effect of the fluid preloading during spinal anesthesia [27]. Fluid preloading might prevent a decrease in 
central venous pressure and cardiac index, but blood pressure decreased because of a substantial decrease in systemic vascular resistance [28]. Some studies have shown that the incidence of hypotension decreased in the first several minutes following subarachnoid injection by fluid preloading, and that after that it is hard to prevent hypotension without medication [29]. Although fluid preloading does not effectively prevent hypotension after spinal anesthesia, the present study showed the possibility of fluid preloading to prevent bradycardia after dexmedetomidine administration. Second, fluid preloading can cause diverse complications such as pulmonary edema or urinary retention [28]. Although many studies have reported that fluid preloading during spinal anesthesia did not cause serious side effects in healthy adult patients [29], anesthesiologist have to consider the possibility of pulmonary edema, especially in high risk patients such as those of old age and patients with congestive heart failure. Third, the present study used fluid preloading to prevent bradycardia after dexmedetomidine administration, but bradycardia after dexmedetomidine infusion was easily controlled with IV atropine $[6-8,11,12]$. It seems unreasonable to accept a risk of pulmonary edema to prevent easily controllable bradycardia. However, bradycardia after dexmedetomidine infusion can also cause severe complications such as cardiac arrest [30]. Fluid preloading has been used usually to prevent hypotension induced by spinal anesthesia. We wanted to suggest that fluid preloading is effective in preventing bradycardia induced by spinal anesthesia as well as hypotension and can be used as an option for the prevention of bradycardia induced by spinal anesthesia. Overall, both fluid preloading and dexmedetomidine infusion can cause serious consequences. Therefore, fluid preloading to prevent bradycardia after dexmedetomidine administration must be executed with careful consideration about risks and benefits.

The present study has several limitations. First, as previously mentioned, to access the volume status, TFCd was used. Since TFCd has not been studied a lot, additional research is needed to ensure the reliability. In addition, the TFCd at PACU could not be measured, since the power could not be supplied to instrument during transport to PACU. Second, the authors suggested the Bainbridge reflex as the mechanism of reduced bradycardia after fluid loading. However, it is not clear whether the bradycardia was induced by
Bainbridge reflex, since the present study is limited to clinical research. To clarify this, additional experiments about atrial pressure and reflex are needed. Third, the fluid redistribution by leg position change during operation could not be controlled. To minimize the fluid redistribution during operation, the tourniquet was turned on at a unified time, and the tilting of the surgical bed was minimized in present study. However, the positions of the legs were changed often during operation, and these position changes could cause fluid redistribution. Although the authors could not control the change of leg position, the measured $\mathrm{HR}, \mathrm{MBP}$, and TFCd values were not changed significantly by the leg position change.

In conclusion, fluid loading during spinal anesthesia can reduce the incidence and extent of bradycardia after IV dexmedetomidine infusion in patients with spinal anesthesia. The present study showed that $12 \mathrm{ml} / \mathrm{kg}$ of crystalloid loading over 30 min can reduce the incidence and extend of bradycardia without complication. However, the possible complications and risks and benefits of fluid preloading should be considered.

\section{CONFLICTS OF INTEREST}

No potential conflict of interest relevant to this article was reported.

\section{ORCID}

Wonjin Lee: https://orcid.org/0000-0002-6240-7370

Yongjae Han: https://orcid.org/0000-0001-7321-1376

Sung-ho Moon: https://orcid.org/0000-0002-3602-9441

Kwangrae Cho: https://orcid.org/0000-0002-9805-9582

Myoung-hun Kim: https://orcid.org/0000-0002-4350-0078

\section{REFERENCES}

1. Wu CL, Naqibuddin M, Fleisher LA. Measurement of patient satisfaction as an outcome of regional anesthesia and analgesia: a systematic review. Reg Anesth Pain Med 2001; 26: 196-208.

2. Kim DS, Na HS, Lee JH, Shin YD, Shim JK, Shin HW, et al. Current clinical application of dexmedetomidine for sedation and anesthesia. Anesth Pain Med 2017; 12: 306-19.

3. De Andrés J, Valia JC, Gil A, Bolinches R. Predictors of patient 
satisfaction with regional anesthesia. Reg Anesth 1995; 20: 498505.

4. Reddy VS, Shaik NA, Donthu B, Reddy Sannala VK, Jangam V. Intravenous dexmedetomidine versus clonidine for prolongation of bupivacaine spinal anesthesia and analgesia: a randomized double-blind study. J Anaesthesiol Clin Pharmacol 2013; 29: 3427.

5. Abdallah FW, Abrishami A, Brull R. The facilitatory effects of intravenous dexmedetomidine on the duration of spinal anesthesia: a systematic review and meta-analysis. Anesth Analg 2013; 117:271-8.

6. Dinesh CN, Sai Tej NA, Yatish B, Pujari VS, Mohan Kumar RM, Mohan CV. Effects of intravenous dexmedetomidine on hyperbaric bupivacaine spinal anesthesia: a randomized study. Saudi J Anaesth 2014; 8: 202-8.

7. Elcicek K, Tekin M, Kati I. The effects of intravenous dexmedetomidine on spinal hyperbaric ropivacaine anesthesia. J Anesth 2010; 24: 544-8.

8. Hong JY, Kim WO, Yoon Y, Choi Y, Kim SH, Kil HK. Effects of intravenous dexmedetomidine on low-dose bupivacaine spinal anaesthesia in elderly patients. Acta Anaesthesiol Scand 2012; 56: 382-7.

9. Jung SH, Lee SK, Lim KJ, Park EY, Kang MH, Lee JM, et al. The effects of single-dose intravenous dexmedetomidine on hyperbaric bupivacaine spinal anesthesia. J Anesth 2013; 27: 380-4.

10. Lee MH, Ko JH, Kim EM, Cheung MH, Choi YR, Choi EM. The effects of intravenous dexmedetomidine on spinal anesthesia: comparision of different dose of dexmedetomidine. Korean J Anesthesiol 2014; 67: 252-7.

11. Al-Mustafa MM, Badran IZ, Abu-Ali HM, Al-Barazangi BA, Massad IM, Al-Ghanem SM. Intravenous dexmedetomidine prolongs bupivacaine spinal analgesia. Middle East J Anaesthesiol 2009; 20: 225-31.

12. Tekin M, Kati I, Tomak Y, Kisli E. Effect of dexmedetomidine IV on the duration of spinal anesthesia with prilocaine: a doubleblind, prospective study in adult surgical patients. Curr Ther Res Clin Exp 2007; 68: 313-24.

13. Crystal GJ, Salem MR. The Bainbridge and the "reverse" Bainbridge reflexes: history, physiology, and clinical relevance. Anesth Analg 2012; 114: 520-32.

14. Greene N. Preganglionic sympathetic blockade in man: a study of spinal anesthesia. The Torsten Gordh lecture, 1980. Acta Anaesthesiol Scand 1981; 25: 463-9.

15. Ramsay MA, Savege TM, Simpson BR, Goodwin R. Controlled sedation with alphaxalone-alphadolone. Br Med J 1974; 2: 656-9.
16. Whizar-Lugo V, Gómez-Ramírez IA, Cisneros-Corral R, Martínez-Gallegos N. Intravenous dexmedetomidine vs. intravenous clonidine to prolong bupivacaine spinal anesthesia. A double blind study. Anest en Mexico 2007; 19: 143-6.

17. Kaur M, Singh PM. Current role of dexmedetomidine in clinical anesthesia and intensive care. Anesth Essays Res 2011; 5: 128-33.

18. Mittal G, Gupta K, Katyal S, Kaushal S. Randomised double-blind comparative study of dexmedetomidine and tramadol for postspinal anaesthesia shivering. Indian J Anaesth 2014; 58: 257-62.

19. Hsu YW, Cortinez LI, Robertson KM, Keifer JC, Sum-Ping ST, Moretti EW, et al. Dexmedetomidine pharmacodynamics: part I: crossover comparison of the respiratory effects of dexmedetomidine and remifentanil in healthy volunteers. Anesthesiology 2004; 101: 1066-76.

20. Mason KP, Zurakowski D, Zgleszewski S, Prescilla R, Fontaine PJ, Dinardo JA. Incidence and predictors of hypertension during high-dose dexmedetomidine sedation for pediatric MRI. Paediatr Anaesth 2010; 20: 516-23.

21. Sudheesh K, Harsoor S. Dexmedetomidine in anaesthesia practice: a wonder drug? Indian J Anaesth 2011; 55: 323-4.

22. Sancetta SM, Lynn RB, Simeone FA, Scott RW. Studies of hemodynamic changes in humans following induction of low and high spinal anesthesia: I. general considerations of the problem. The changes in cardiac output, brachial artery pressure, peripheral and pulmonary oxygen contents and peripheral blood flows induced by spinal anesthesia in humans not undergoing surgery. Circulation 1952; 6: 550-71.

23. Carpenter RL, Caplan RA, Brown DL, Stephenson C, Wu R. Incidence and risk factors for side effects of spinal anesthesia. Anesthesiology 1992; 76: 906-16.

24. Baron JF, Decaux-Jacolot A, Edouard A, Berdeaux A, Samii K. Influence of venous return on baroreflex control of heart rate during lumbar epidural anesthesia in humans. Anesthesiology 1986; 64: 188-93.

25. Kossari N, Hufnagel G, Squara P. Bioreactance: a new tool for cardiac output and thoracic fluid content monitoring during hemodialysis. Hemodial Int 2009; 13: 512-7.

26. Hamed AMS, Talaat SM. Effect of intravenous versus intrathecal low-dose dexmedetomidine on spinal block in lower limb orthopedic surgery. Ain-Shams J Anaesthesiol 2014; 7: 205-210.

27. Jackson R, Reid JA, Thorburn J. Volume preloading is not essential to prevent spinal-induced hypotension at caesarean section. Br J Anaesth 1995; 75: 262-5.

28. Ben-David B, Frankel R, Arzumonov T, Marchevsky Y, Volpin G. Minidose bupivacaine-fentanyl spinal anesthesia for surgical 
repair of hip fracture in the aged. Anesthesiology 2000; 92: 6-10.

29. Bajwa SJ, Kulshrestha A, Jindal R. Co-loading or pre-loading for prevention of hypotension after spinal anaesthesia! A therapeu- tic dilemma. Anesth Essays Res 2013; 7: 155-9.

30. Ingersoll-Weng E, Manecke GR Jr, Thistlethwaite PA. Dexmedetomidine and cardiac arrest. Anesthesiology 2004; 100: 738-9. 